\title{
DEVELOPMENT OF A METHOD AND ALGORITHM FOR INHIBITING AN AUTOMATIC TRANSFER SWITCH OF THE CIRCUIT BREAKER FOR A SUSTAINED SHORT-CIRCUIT
}

\author{
Igor Nikolaevich Fomin ${ }^{1,}{ }^{*}$, Roman Pavlovich Belikov ${ }^{1}$,Tatyana Anatolyevna Kudinova ${ }^{1}$, and Nailya Kamilevna Miftakhova ${ }^{2}$ \\ ${ }^{1}$ Orel State Agrarian University named after N.V. Parakhin, Orel, Russia \\ ${ }^{2}$ Kazan State Power Engineering University, Kazan, Russia
}

\begin{abstract}
Circuit breakers with automatic transfer switches (ATS) are designed in such a way that when the voltage disappears during a short-circuit (SC) in the ring network line, the ATS device is triggered. At the same time, its switch is turned on at short-circuit, then it is turned off with acceleration. Even a shortterm switching on of the automatic transfer switch for a sustained short-circuit leads to emergency situations $[1,2]$. The electrical equipment of the ring network spare line is exposed to high emergency short-circuit currents, and the consumers powered by the spare transformer are turned off. It is possible to minimize and eliminate the damages caused by the above mentioned cases by inhibiting the switching on of the circuitbreaker of the automatic transfer switch.
\end{abstract}

\section{Introduction}

This method makes it possible to inhibit the switching on of the circuit breaker of the automatic transfer switch in the ring network for a sustained short-circuit; meanwhile, it is based on the principles of remote control of the operation of the circuit-breakers [3]. The method gives the opportunity to determine the location of the short circuit. In case, if it happened on a section of the line, adjacent to the circuit-breaker of the automatic transfer switch, then the switching on for a stable short circuit of the ATS circuit-breaker is inhibited [4,5].

For this purpose, at the beginning of the overhead line, powered from the busbars of the power source, the short-circuit current is monitored. In this case, from the moment the short-circuit current appears, the amount of time, set by the operation time of the protection of the sectionalizing circuit-breaker, located in the power supply line together with the network ATS point, is counted $[6,7]$.

Next, the time of the appearance of the second inrush of the short-circuit current is monitored by controlling the time of the no-current pause of the automatic reclosing after the disappearance of the short-circuit current at the end of the first inrush of the short-circuit current. The operation time of the protection of the sectionalizing circuit-breaker is counted; and if after this period of time the second inrush of the short-circuit current disappears, then the fact of a sustained shortcircuit in this line is determined. Next, an inhibition signal to switch on the circuit-breaker of the automatic transfer switch is given and the presence of a sustained short circuit in this line is established.

\section{Theoretical research}

The work of the method for inhibitingan automatic transfer switch of the circuit-breakerfor a sustained short circuit is carried out as follows.In normal mode of operation, the sectionalizing circuit-breaker is on and the circuit-breaker of the automatic transfer switch point is off.At the output, due to the operating current,there is a certain value of the output signal, not sufficient for the operation of the short-circuit current sensor, therefore the presence of the output signal at one of the inputs of the circuit elements is insufficient for their operation. Thecircuitdoesnotstart [8].

In case of a short circuit, the value of the output signal is sufficient to actuate the short-circuit current sensor, therefore a signal appears at its output.The signal is memorized by the MEMORY element and is fed to the input of the DELAY element, from the output of which the signal will appear after a time interval equal to the delay time of the protection operation of the sectionalizing circuit-breaker.The signal that existed at the output of the element at the moment of the appearance of the first inrush of the short-circuit current will disappear, and at the moment of disconnection of this inrush short-circuit current, it will reappear and go to the first input of the element.Thus, the presence of two input signals will lead to the appearance of a signal at its output, which will go to the input of the MEMORY element, be remembered by it and will go to the input of the DELAY element.At the output of this element, the signal will appear after a time equal to the time of the no-current pause of the automatic closing of the

*Corresponding author: igor.fom-in@yandex.ru 
automatic reclosing of the sectionalizing circuitbreaker.At this moment, as a result of automatic reclosing of the sectionalizing circuit-breaker, a shortcircuit current reappears; therefore, a signal will also come from the short-circuit current sensor to the first input of the element.The presence of two input signals on this element will result in its output signal.It will go to the input of the MEMORY element, will be remembered by it, and will ensure the presence of an input signal at the DELAY element.From the output of this element, the signal will appear after a time equal to the operation time of the protection of the sectionalizing circuit-breaker and it will appear at the input of the SINGLE-VIBRATOR element.The SINGLEVIBRATOR element will give a single impulse, which will go to the MEMORY elements, will "reset" them. And if at this moment of time the disappearance of the second inrush of the short-circuit current occurs, then the fact of repeated disconnection of the sectionalizing circuit-breakerand the presence of a sustained shortcircuit in the line are established. A signal will appear at the output of the element, which will ensure the inhibition of switching on for a sustained short circuit of the circuit-breaker of the automatic transfer switch in the ring network.

To implement this method of inhibition, an algorithm has been developed. Herewith, the initial stage of the algorithm provides for the presence of the operating current and the minimum short-circuit current, as well as the delay time for the automatic reclosing of the circuitbreaker[9,10,11].

This algorithm served as the basis for creating means of implementing the inhibition of the automatic transfer switch of the circuit-breaker for a sustained shortcircuit.It does not matter on what element base the technical implementation of this method will be performed.It should be noted that the inhibition signal can be simultaneously applied not only to the automatic transfer switch circuit, but also to the server for storing and processing information about the network state. [10].

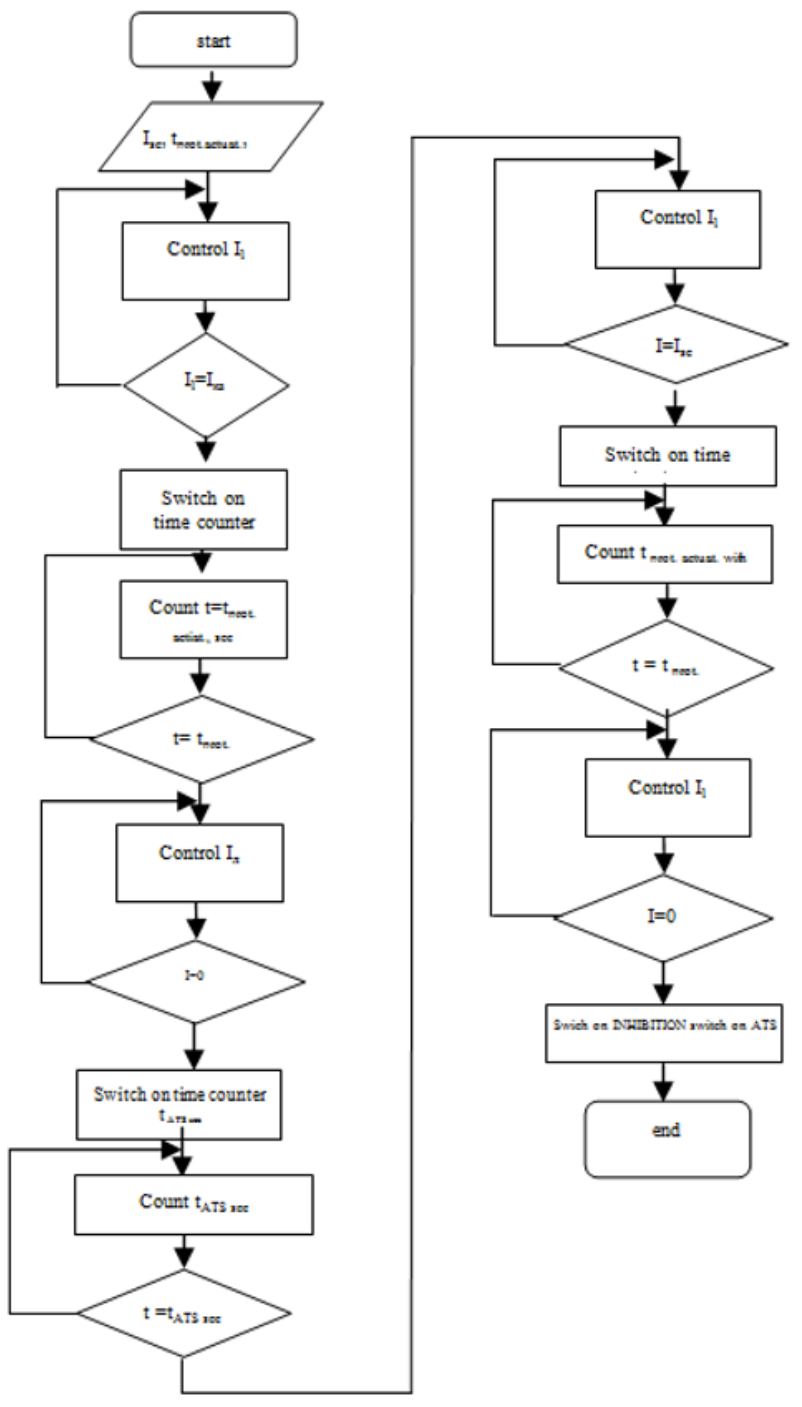

Fig. 1.Algorithm for the implementation of the method for inhibiting the switching on of the circuit-breaker of the automatic transfer switch in the ring network.

\section{Technical implementation}

The proposed method for inhibiting the automatic transfer switch of the circuit- breaker for a sustained short circuit is implemented in a device installed in the ring network line. The device is made on the basis of an analog-to-digital converter, from which information is transmitted to the server for storing and processing information through wireless communication channels.

The device consists of a block for connecting a current sensor and a block for converting and analyzing the input signal, which is also necessary for the formation and transmission of digital data to a computer for further analysis [11,12] (Figure 2).

A series of experiments was carried out for a detailed check of the remote control functionality. During the experiments, the magnitude of the current surges issued by the simulator varied within the range from the minimum value to the maximum possible short-circuit current. (30 A in current circuits). 


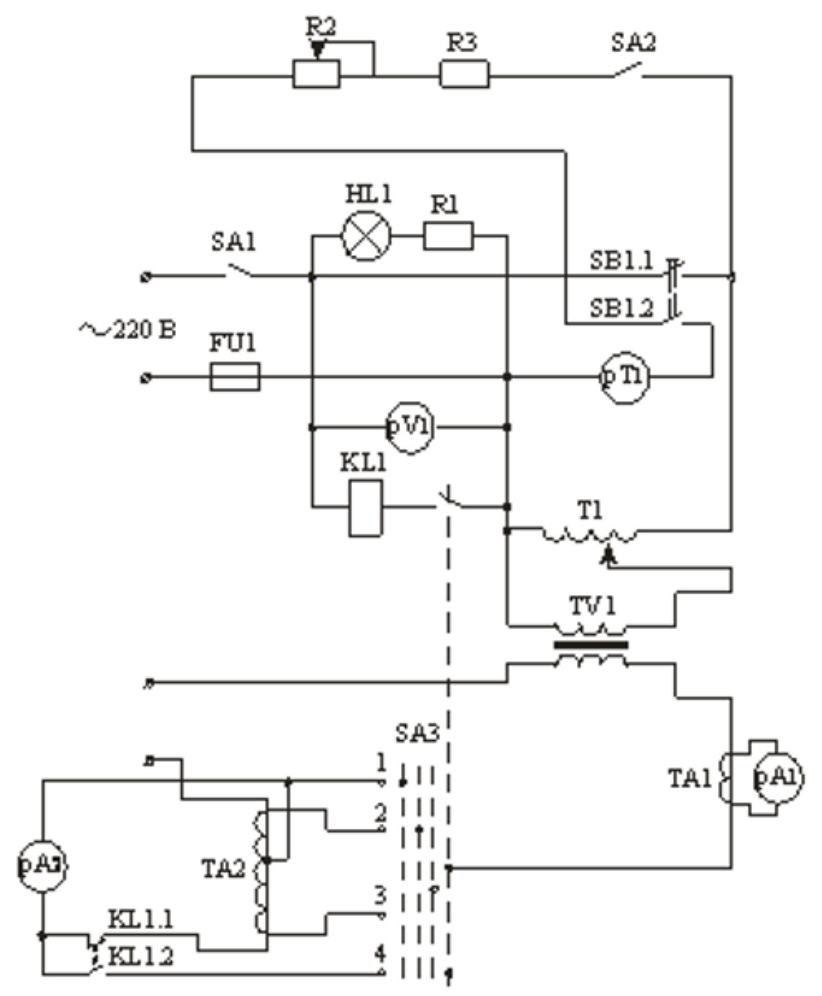

Fig. 2.Schematic diagram of a current simulator (SA1, SA2 circuit-breakers; FU1 - fuse; HL1 - light signaling; R1, R3 load resistance; SB1.1, SB1.2 - push-button station contacts; R2 - controlled resistance; pT1 - electric stopwatch; pV1 voltmeter; KL1 - intermediate relay; T1 - autotransformer; SA3 - switch; TV1 - voltage transformer; pA1, pA2 ammeters; KL1.1, KL1.2 - opening and closing contacts of the intermediate relay; TA1, TA2 - current transformers).

In addition, the current value of the sectionalized line was changed from zero to the maximum possible value taken with a large margin $(5 \mathrm{~A})$. The data are displayed as a waveform.

The experiments carried out during laboratory tests were made several times. Moreover, at first, several similar situations were repeated in a row, and then these situations were carried out randomly $[13,14]$.

\section{Conclusions}

Thus, the use of the inhibition of automatic transfer switch of the circuit-breaker for a sustained short circuit allows:

1. to inhibit the switching on of an automatic transfer switch of the circuit-breaker for a sustained short circuit both with two- and three-phase sustained short-circuit in lines with sectionalized points;

2. the developed technical means for the implementation of this method make it possible to increase the reliability of power supply to consumers due to the fact that tripping of the switch of the automatic transfer switch for sustained short circuits will be excluded.

\section{References}

[1] I.N. Fomin, L.D. Surov, Remote Control over the Actions of Switches in the Ring Network, Bulletin of Orel State Agrarian University 5, 38, 163-166 (2012)

[2] L.D. Surov, I.N. Fomin, V.F. Shumarin, Monitoring the Operation of the Switch of the ATS Network Point for Short Circuits in the Ring Network, Mechanization and Electrification of Agriculture 3, 38, 18-20 (2009)

[3] I.N. Fomin, L.D. Surov, Remote Control over the Actions of Switches in the Ring Network, Bulletin of Orel State Agrarian University 5, 38, 163-166 (2012)

[4] L.D. Surov, I.N. Fomin, Patent no. 2305356 C1 Russian Federation, Method for Monitoring Successful and Unsuccessful Automatic Reclosing of Circuit Breakers in a Sectionalized Line of a Ring Network, Applicant and patent holder FSEE HPE Orel State Agrarian University, 2006118486/09, declare 29.05.2006

[5] L.D. Surov, I.N. Fomin, D.N. Fomin, Patent no. 2394331 C1 10.07.2010, Russian Federation, Method for Monitoring the Disconnection of the Main Switch of the Line in Case of Failure to Open the Sectionalized Switch When it is Turned on Again for a Stable Short Circuit in the Ring Network, Applicant and patent holder FSEE HPE Orel State Agrarian University, 2009118084/09, declare 12.05.2009

[6] I.N. Fomin, Inhibition of Switching on the ATS Switch During Remote Control of Emergency Outages in the Power Line, National University of Bioresources and Environmental Management Ukraine, Series: Technique and Power Engineering of Agro-Industrial Complex 209, 2, 111-117 (2015)

[7] L.D. Surov, I.N. Fomin, I.L. Surov, D.N. Fomin, Patent no. 2421862 Russian Federation, MPK H02J 9/06 H02J 13/00, The Method of Inhibiting the Network Automatic Transfer Switch for Short Circuit, Applicant and patent holder FSEE HPE Orel State Agrarian University, 2010109117/07, declare 11.03.2010, publ. 20.06.2011, bul. no. 17, 7

[8] L.D. Surov, I.N. Fomin, Monitoring the Unsuccessful Automatic Reclosing of the Sectionalizer, Electro, Electrical Engineering, Power Engineering, Electrical Industry 6, 46-48 (2009)

[9] L.D. Surov, I.N. Fomin, Monitoring the Successful Automatic Reclosing of Sectionalized Switches in a Ring Line, Bulletin of Orel State Agrarian University 1, 22, 23-25 (2010)

[10] I.N. Fomin, L.D. Surov, Block diagram of Inhibition of Network Automatic Transfer Switch, Agrotechnics and Energy Supply 1, 1, 461-464 (2014)

[11]L.D. Surov, I.N. Fomin, Monitoring the Circuit Breaker Tripping in a Sectionalized Line of a Ring Network, State and Prospects of Energy and 
Resource-Saving Technologies in the AgroIndustrial Complex, Materials of the International Scientific and Practical Conference, 173-177 (2009)

[12] A.V. Vinogradov, S.M. Astakhov, N.S. Sorokin, Remote Control of Circuit Breakers Tripping in Distribution Networks, Agricultural Mechanization and Electrification, 12, 44-46 (2008)

[13]A.V. Vinogradov, A.N. Vasiliev, V.E. Bolshev, A.V. Vinogradova, T.A. Kudinova, N.S. Sorokin, N.V. Gruntovich, Methods of Reducing the Power Supply Outage Time of Rural Consumers, Renewable Energy and Power Supply Challenges for Rural Regions, Ser. Premier reference source, Hershey, PA, USA, 370-392 (2019)

[14] R.P. Belikov, A.E. Semenov, I.N. Fomin, Methods and Technical Means of improving the Power Quality in Rural Electrical Networks, Innovative Development of the University Library: Management and Marketing, Materials of the II Scientific-Practical Conference, 60-65 (2018) 